\title{
A Case of Multicentric Castleman's Disease of Mixed-Type, which Showed Constellation of Symptoms, i.e., Thrombocytopenia, Anasarca, Anemia, Fever, Myelofibrosis, and Lymphadenopathy
}

\author{
Nobuyasu Awano, ${ }^{1)}$ Minoru Inomata, ${ }^{1)}$ Yui Sonoda, ${ }^{1)}$ Keisuke Kondoh, ${ }^{1)}$ Ryu Ono, ${ }^{1)}$ Atsuko Moriya, ${ }^{1)}$ \\ Tsunehiro Ando, ${ }^{1)}$ Toshio Kumasaka, ${ }^{2)}$ Tamiko Takemura, ${ }^{2)}$ Kengo Takeuchi, ${ }^{3)}$ \\ and Soichiro Ikushima ${ }^{1)}$
}

Keywords: TAFRO syndrome, multicentric Castleman's disease (MCD), tocilizumab, interleukin-6

\section{TO THE EDITOR}

Multicentric Castleman's disease (MCD) is a systemic disease characterized by generalized lymphadenopathy and the proliferation of plasma cells. Recently, Takai et al. reported three patients showing a constellation of symptoms ; thrombocytopenia, anasarca, fever, reticulin fibrosis and organomegaly (TAFRO syndrome). ${ }^{1}$ We present a case of MCD developing in a 78 -year-old woman with a 17 -year history of sarcoidosis, which had several features of TAFRO syndrome. The first part of this patient's clinical course has already been reported. ${ }^{2}$ Here, we report the all parts of the clinical course, from diagnosis to death. The administration of steroid-pulse therapy and prednisolone was ineffective, although treatment with tocilizumab proved highly effective. But 15 months after initiation of tocilizumab, the patient died of disease progression and complications.

A 60-year-old woman was diagnosed as sarcoidosis in 1993 according to the criteria by the laboratory data (the elevation of serum angiotensin-converting enzyme to 23.6 $\mathrm{IU} / \mathrm{L}$ and lysozyme to $10.8 \mu \mathrm{g} / \mathrm{mL}$ ) and skin and breast biopsies (non-caseating epithelioid cell granulomas). ${ }^{3}$ She was

\section{Received : January 25, 2013}

Revised : March 4, 2013

Accepted: March 5, 2013

1) Department of Respiratory Medicine, Japanese Red Cross Medical Center, Tokyo, Japan

${ }^{2)}$ Department of Pathology, Japanese Red Cross Medical Center, Tokyo, Japan

${ }^{3)}$ Department of Pathology, the Cancer Institute Hospital of JFCR, Tokyo, Japan Corresponding author: Dr. Nobuyasu Awano, Department of Respiratory Medicine, Japanese Red Cross Medical Center, 4-1-22 Hiroo, Shibuya-ku, Tokyo 150-8935, Japan

E-mail address : awanobu0606@hotmail.co.jp followed by observation without the administration of any treatment but in 2003, she developed third-degree atrioventricular block as a result of cardiac sarcoidosis. A pacemaker was implanted, and again she was followed by observation. In December 2010, at the age of 77, the patient came to our hospital with a slight fever and epigastric pain. Two weeks later, she developed dyspnea and systemic edema and was admitted to our hospital. Her weight had increased from 48.0 to $57.1 \mathrm{~kg}$ in one month. A physical examination revealed bilateral cervical and axillary lymph node swelling and legpitting edema; however, no rheumatological, dermatological, neurological or ophthalmological abnormalities were observed. The laboratory findings showed a white blood cell count of $8,600 / \mu \mathrm{L}$; however, the C-reactive protein level had increased to $15.94 \mathrm{mg} / \mathrm{dL}$. A coagulation disorder was evident with a fibrin/fibrinogen degradation product level of 51.3 $\mu \mathrm{g} / \mathrm{mL}$ and a D-dimer level of $24.9 \mu \mathrm{g} / \mathrm{mL}$. While the serum levels of calcium, angiotensin-converting enzyme, lysozyme, IgG and IgG4 were within normal limits, the serum interleukin-6 (IL-6) level was found to have increased slightly to $18 \mathrm{pg} / \mathrm{mL}$. The serum level of vascular endothelial growth factor increased to $69.4 \mathrm{pg} / \mathrm{ml}$. Human herpesvirus-8 (HHV8) DNA was not found in the serum. Table 1 shows additional data. A serological test for human immunodeficiency virus (HIV) was negative, as were both quantiFERON®-TB and tuberculin tests. The arterial blood gas test was unremarkable, and cultures of blood, sputum and the fluids of ascites and pleural effusion were sterile. A closer inspection of the ascites and pleural effusion revealed unremarkable results, except for a marked increase in the IL-6 levels (Fig. 3). Chest radiography showed bilateral hilar lymphadenopathy and dull costophrenic angles; however, no abnormal opacities were 
Table 1. Laboratory data

\begin{tabular}{|c|c|c|c|c|c|}
\hline White blood cell & $8,600 / \mu \mathrm{L}$ & $\mathrm{Na}$ & $136 \mathrm{mEq} / \mathrm{L}$ & \multicolumn{2}{|c|}{ Pleural effusion } \\
\hline Red blood cell & $380 \times 10^{4} / \mu \mathrm{L}$ & $\mathrm{K}$ & $4.8 \mathrm{mEq} / \mathrm{L}$ & Albumin & $1.2 \mathrm{~g} / \mathrm{dL}$ \\
\hline Hemoglobin & $10.3 \mathrm{~g} / \mathrm{dL}$ & $\mathrm{Cl}$ & $106 \mathrm{mEq} / \mathrm{L}$ & TG & $6 \mathrm{mg} / \mathrm{dL}$ \\
\hline Platelet & $16.0 \times 10^{4} / \mu \mathrm{L}$ & $\mathrm{Ca}$ & $7.2 \mathrm{mg} / \mathrm{dL}$ & Protein & $2,400 \mathrm{mg} / \mathrm{dL}$ \\
\hline Prothrombin time & $70 \%$ & $\mathrm{Fe}$ & $7 \mu \mathrm{g} / \mathrm{dL}$ & Glucose & $148 \mathrm{mg} / \mathrm{dL}$ \\
\hline PT-INR & 1.17 & Glucose & $106 \mu \mathrm{g} / \mathrm{dL}$ & LDH & $56 \mathrm{IU} / \mathrm{L}$ \\
\hline APTT & $46.2 \mathrm{sec}$ & ACE & $5.6 \mathrm{IU} / \mathrm{L}$ & Hyaluronic acid & $24,400 \mathrm{ng} / \mathrm{dL}$ \\
\hline Fibrinogen & $543 \mathrm{mg} / \mathrm{dL}$ & BNP & $126.0 \mathrm{pg} / \mathrm{mL}$ & CEA & $0.6 \mathrm{ng} / \mathrm{mL}$ \\
\hline FDP & $51.3 \mu \mathrm{g} / \mathrm{mL}$ & SCC & $0.6 \mathrm{ng} / \mathrm{mL}$ & CYFRA & $1.3 \mathrm{ng} / \mathrm{mL}$ \\
\hline D-dimer & $24.9 \mu \mathrm{g} / \mathrm{mL}$ & CYFRA & $1.3 \mathrm{ng} / \mathrm{mL}$ & ADA & $6.7 \mathrm{IU} / \mathrm{L}$ \\
\hline Total protein & $5.4 \mathrm{~g} / \mathrm{dL}$ & NSE & $8.3 \mathrm{ng} / \mathrm{mL}$ & Cytology & Class II \\
\hline Albumin & $2.5 \mathrm{~g} / \mathrm{dL}$ & Lysozyme & $9.7 \mu \mathrm{g} / \mathrm{mL}$ & \multicolumn{2}{|c|}{ Ascites } \\
\hline AST & $26 \mathrm{IU} / \mathrm{L}$ & CRP & $15.94 \mathrm{mg} / \mathrm{dL}$ & TG & $20 \mathrm{mg} / \mathrm{dL}$ \\
\hline ALT & $19 \mathrm{IU} / \mathrm{L}$ & $\operatorname{IgG}$ & $1,066 \mathrm{mg} / \mathrm{dL}$ (polyclonal pattern) & Protein & $2,700 \mathrm{mg} / \mathrm{dL}$ \\
\hline LDH & $148 \mathrm{IU} / \mathrm{L}$ & sIL-2 R & $1,630 \mathrm{U} / \mathrm{mL}$ & Glucose & $15 \mathrm{mg} / \mathrm{dL}$ \\
\hline ALP & $459 \mathrm{IU} / \mathrm{L}$ & IL-6 & $18 \mathrm{pg} / \mathrm{mL}$ & $\mathrm{LDH}$ & $65 \mathrm{IU} / \mathrm{L}$ \\
\hline T-chol & $95 \mathrm{mg} / \mathrm{dL}$ & $\operatorname{IgG} 4$ & $31 \mathrm{mg} / \mathrm{dL}$ & CEA & $0.5 \mathrm{ng} / \mathrm{mL}$ \\
\hline BUN & $15 \mathrm{mg} / \mathrm{dL}$ & VEGF & $69.4 \mathrm{pg} / \mathrm{mL}$ & CA19-9 & $1 \mathrm{U} / \mathrm{mL}$ \\
\hline Creatinine & $0.93 \mathrm{mg} / \mathrm{dL}$ & & & Cytology & Class II \\
\hline
\end{tabular}

PT-INR, prothrombin time-international normalized ratio ; APTT, activated partial thromboplastin time ; FDP, fibrin/fibrinogen degradation products ; AST, aspartate aminotransferase ; ALT, alanine transaminase ; LDH, lactate dehydrogenase ; T-chol, total cholesterol ; ALP, alkaline phosphatase ; BUN, blood urea nitrogen; ACE, angiotensin converting enzyme ; BNP, brain natriuretic peptide ; SCC, squamous cell carcinoma antigen; CYFRA, cytokeratin 19 fragment; NSE, neuron specific enolase; CRP, C-reactive protein; sIL-2 R, soluble interleukin-2 receptor; VEGF, vascular endothelial growth factor; TG, triglyceride; CEA, carcinoembryonic antigen; ADA, adenosine deaminase ; CA19-9, cancer antigen 19-9
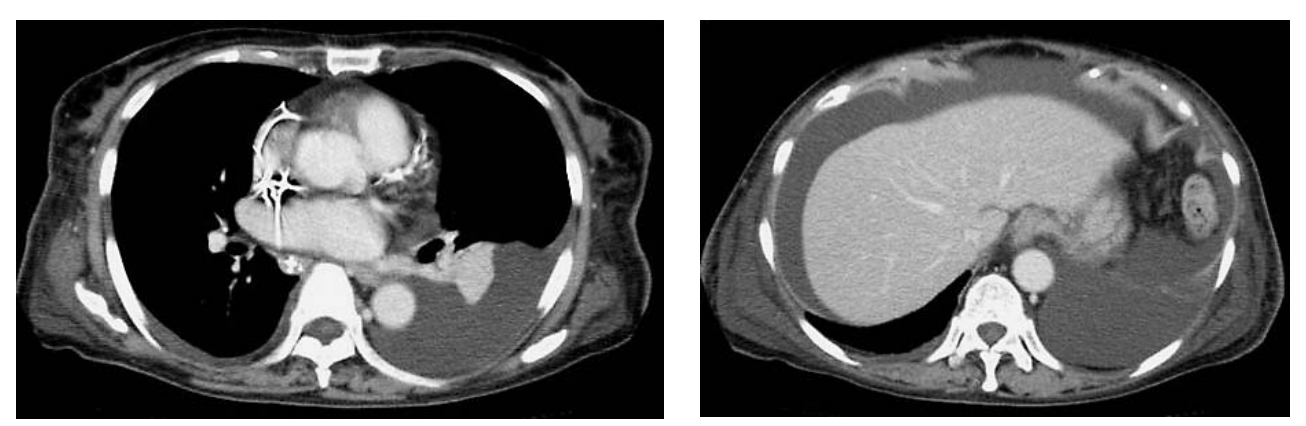

Fig. 1. Computed tomography showed bilateral pleural effusion and ascites. Lymph nodes in the bilateral cervix, axilla, hilum, mediastinum and abdominal cavity showed swelling. There were neither abnormal opacities in the lungs nor hepatosplenomegaly.

observed in the lung lesion. Computed tomography showed multiple lymphadenopathies, ascites and pleural effusion but did not show hepatosplenomegaly (Fig. 1). Both electrocardiogram and transthoracic ultrasonic cardiograph were normal, and Gallium scintigraphy showed no abnormal uptake in the lymph nodes or systemic organs. Histology of a right axillary lymph node biopsy showed two abnormal features : 1) onion skin-like small vessels and CD21-positive follicular dendritic cell proliferation in the germinal center, a characteristic of hyaline-vascular type CD (Fig. 2A \& 2B); and 2) marked interfollicular plasma cell infiltration around the lymphoid follicle, a characteristic of plasma-cell type CD. The dominant cell type was $\lambda$ rather than $\varkappa$ without monoclonality
(Fig. 2C \& 2D). The patient was diagnosed with mixed-type MCD, and there was no evidence of sarcoidosis or any other lymphoproliferative disorders.

After admission, the platelet count decreased gradually while the patient's weight and ascites increased and she developed disseminated intravascular coagulation (DIC). At that time, the bone marrow biopsy and aspiration revealed mild fibrosis while megakaryocyte did not increased $\left(20 / \mathrm{m}^{2}\right)$ (Fig. 2E \& 2F). Neither heparin with antithrombin and gabexate mesilate, thrombomodulin, prednisolone nor steroid pulse therapy (methylprednisolone sodium succinate 1,000 $\mathrm{mg} /$ day for three days) could control the DIC, ascites or pleural effusion. Although the serum IL-6 level was only 

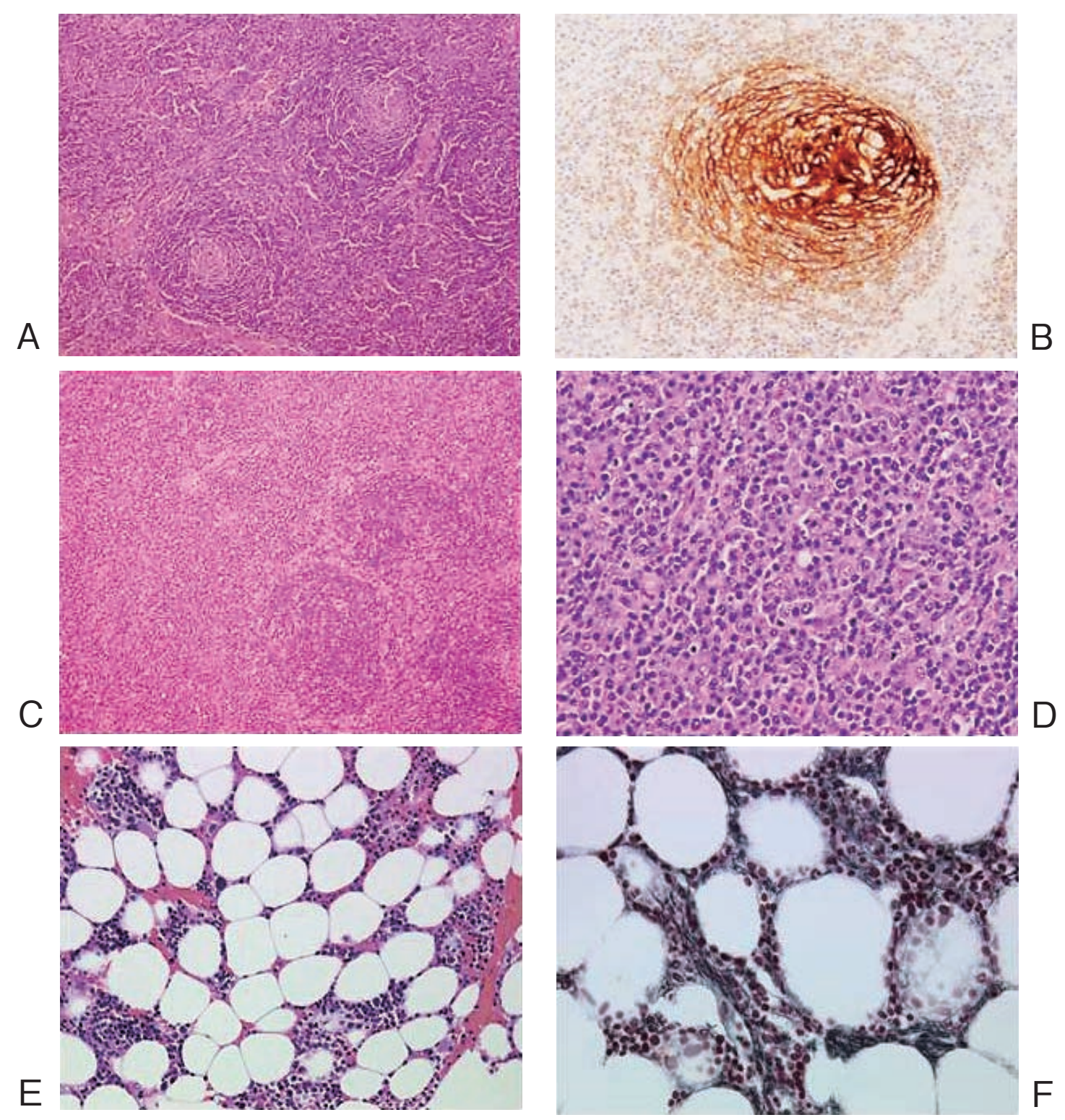

Fig. 2. A right axillary lymph node biopsy showed two characteristic features : $(2 \boldsymbol{A})$ onion skinlike small vessels in the germinal center (H\&E stain) and (2B) CD2 $1^{+}$dendritic cell proliferation in the germinal center (immunostain). (2C) \& (2D) Marked interfollicular plasma cell infiltration (H\&E stain). A bone marrow smear and biopsy showed these features: (2E) Slightly hypocellular bone marrow. No increase in megakaryocyte $\left(20 / \mathrm{mm}^{2}\right)(\mathrm{H} \& \mathrm{E}$ stain) and $(\boldsymbol{2} \boldsymbol{F})$ mild reticulin fibrosis (silver impregnation stain).

slightly elevated, the markedly high levels in the ascites and pleural effusion induced us to administer tocilizumab (400 mg/body) with dramatic results. After the administration of tocilizumab every two weeks, the DIC improved (Fig. 3) and computed tomography showed a complete resolution of the ascites and pleural effusion, as well as the significant shrinking of the lymph nodes. The patient was discharged and tocilizumab treatment has continued to be administered every two weeks. Her condition was stable with no recurrence until
May 2012. But in May 2012, her condition was exacerbated gradually; the serum level of IL-6 was elevated, systemic edema, ascites and pleural effusion could not be controlled and the platelet count decreased to low levels $(<5.0 \times$ $10^{4} / \mu \mathrm{L}$ ) (Fig. 3). In addition, this patient complicated urinary tract infection because of decreased immune function. She admitted to our hospital again and antibiotics were prescribed. She did not coincide with DIC on admission because there were no significant changes in the serum levels of fibrin/fibri- 


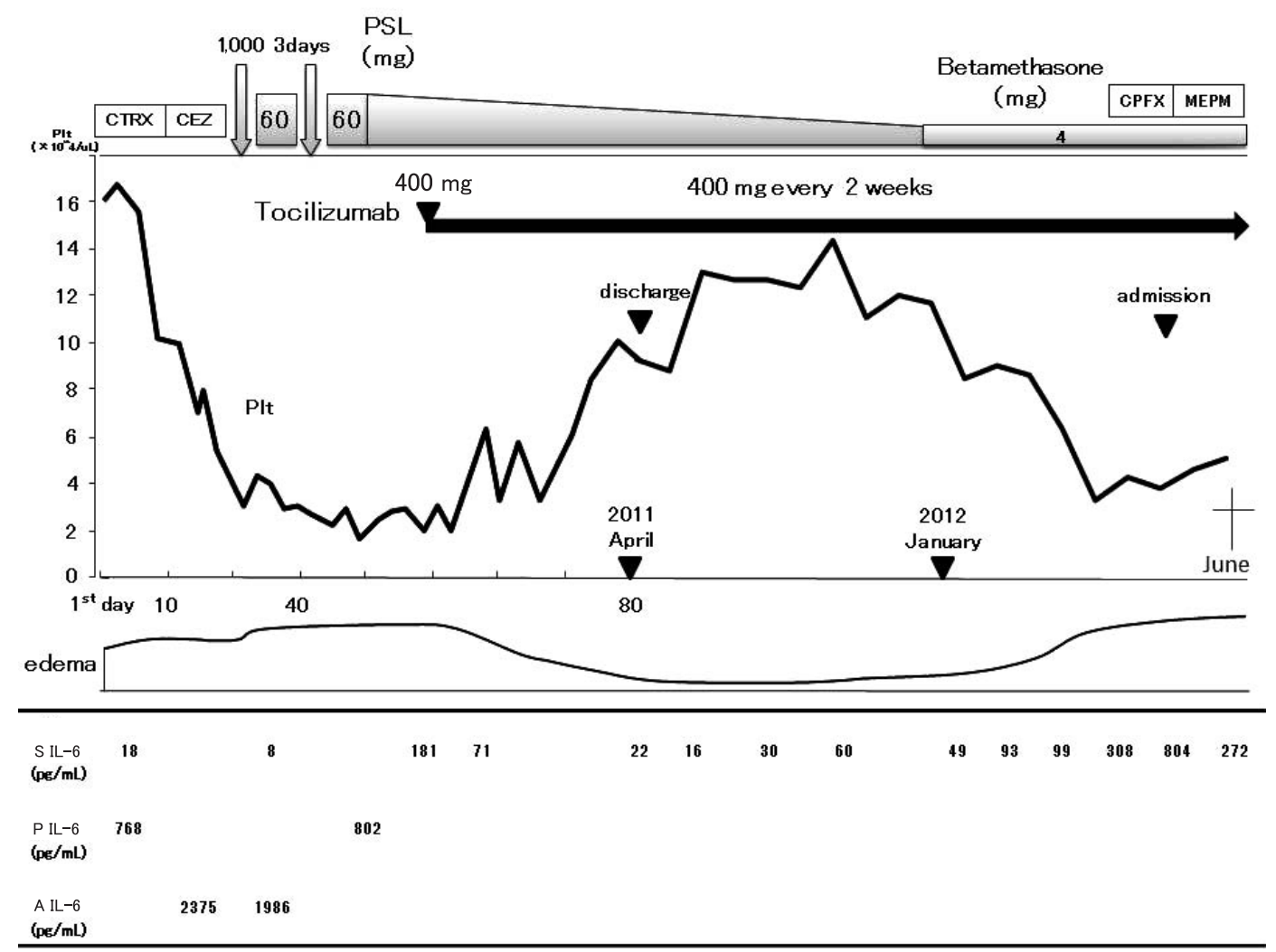

Fig. 3. The patient's clinical course. Plt, platelet; PSL, prednisolone; CTRX, ceftriaxone ; CEZ, cefazolin ; CPFX, ciprofloxacin hydrochloride ; MEPM, meropenem hydrate ; S IL-6, serum interleukin6; P IL-6, pleural effusion interleukin-6; A IL-6, ascites interleukin-6

nogen degradation product, D-dimer, fibrinogen and prothrombin time. The infection had barely improved but laboratory data including platelet count and anasarca were aggravated. The exact cause of thrombocytopenia was unknown because the patient did not be infected with viruses that induced thrombocytopenia including Epstein-Barr virus and cytomegalovirus. Any new medicine was administrated and platelet associated IgG was not detected. In June 2012, 15 months after initiation of tocilizumab, the patient died. The exact cause of death was not determined but the progression of the disease was possibly responsible for her death.

$\mathrm{CD}$ is a lymphoproliferative disorder characterized by enlarged hyperplastic lymph nodes and striking vascular and plasma cell proliferation. ${ }^{3}$ It is associated with HIV, HHV-8, KSHV (Kaposi's sarcoma-associated herpesvirus), secondary amyloidosis and a number of malignancies, including malignant lymphoma, polyneuropathy, organomegaly, endocrinopathy, M-protein and skin change syndrome (POEMS syndrome). ${ }^{4,5}$ The patient was not affected by HIV, HHV-8 and any malignant disease. The patient showed a retention of ascites and pleural effusion. We initially considered POEMS syndrome in the differential diagnosis because the serum level of vascular endothelial growth factor was $69.4 \mathrm{pg} / \mathrm{mL}$, which is characteristic of POEMS syndrome. However, the patient did not exhibit polyneuropathy, monoclonal hyper- $\gamma$ globulinemia, endocrine abnormalities, skin changes or bone lesions, and thus did not meet the current Mayo Clinic criteria for POEMS syndrome. ${ }^{6}$ The patient did not also fulfill the diagnostic criteria for autoimmune diseases including systemic lupus erythematosus. In 2010, Takai et al. reported three patients sharing a constellation of symptoms ; thrombocytopenia, anasarca, fever, reticulin fibrosis and organomegaly (TAFRO syndrome). ${ }^{1}$ In 2012, Kawabata proposed TARIFA syndrome (thrombocytopenia, anemia, renal dysfunction, systemic inflammation, myelofibrosis and ascites) for this pathognomonic syndrome. In September 2012, a research meeting on this syndrome was held at Nagoya. The participants modified TAFRO syndrome, i.e., thrombocytopenia, anasarca, myelofibrosis, renal dysfunction and organomegaly. Thus, the criteria for this syndrome have not been determined in the literature. Although our patient did not completely meet the latest criteria, she had many features listed above.

Although many treatments for MCD are available, no standard therapy has yet been established. There was also no standard approach for the treatment of TAFRO syndrome. In 
this case, steroid-pulse therapy and prednisolone were ineffective. We administered tocilizumab and observed a dramatic improvement as the DIC was eliminated and the retention of pleural effusion and ascites was controlled. But later, tocilizumab could not control the disease progression.

\section{REFERENCES}

1 Takai K, Nikkuni K, Shibuya H, Hashidate H: Thrombocytopenia with mild bone marrow fibrosis accompanied by fever, pleural effusion, ascites and hepatosplenomegaly. Rinsho Ketsueki 51:320-325, 2010 (in Japanese)

2 Awano N, Inomata M, Kondoh K, Satake K, Kamiya H, et al.:
Mixed-type multicentric Castleman's disease developing during a 17-year follow-up of sarcoidosis. Intern Med 51:3061-3066, 2012

3 Herrada J, Cabanillas F, Rice L, Manning J, Pugh W, et al.: The clinical behavior of localized and multicentric Castleman's disease. Ann Intern Med 128:657-662, 1998

4 Castleman B, Iverson L, Menendez VP: Localized mediastinal lymphnode hyperplasia resembling thymoma. Cancer 9:822-830, 1956

5 Oksenhendler E, Duarte M, Soulier J, Cacoub P, Welker Y, et al.: Multicentric Castleman's disease in HIV infection : a clinical and pathological study of 20 patients. AIDS 10:61-67, 1996

6 Dispenzieri A: POEMS syndrome. Blood Rev 21:285-299, 2007 